\title{
Acute renal failure
}

National Diabetes Information Clearinghouse (NDIC)

\section{Definitions}

Kidney

Defined by National Diabetes Information Clearinghouse (NDIC)

Chronic kidney disease (CKD)

Defined by National Diabetes Information Clearinghouse (NDIC)

\section{Source}

National Diabetes Information Clearinghouse (U.S.). (2009). The diabetes dictionary. [Bethesda, Md.]: U.S. Dept. of Health and Human Services, National Institutes of Health, National Institute of Diabetes and Digestive and Kidney Diseases, National Diabetes Information Clearinghouse.

Sudden and temporary loss of kidney function. See chronic kidney disease. 